\title{
Antihyperglycemic Activity of Java Tea-Based Functional Drink- Loaded Chitosan Nanoparticle in Streptozotocin-Induced Diabetic Rats
}

\author{
Monita Rekasih', Tjahja Muhandri', Mega Safithri², Christofora Hanny Wijaya ${ }^{1 *}$ \\ ${ }^{1}$ Departement of Food Science and Technology, Bogor Agricultural University, Bogor, Indonesia \\ ${ }^{2}$ Department of Biochemistry, Graduate School of Bogor Agricultural University, Bogor, Indonesia
}

\section{ARTICLE INFO}

Article history:

Received November 23, 2020

Received in revised form April 15, 2021

Accepted April 30, 2021

KEYWORDS:

Functional drink,

Java tea,

Antihyperglycemic,

Bioavailability,

Nanoencapsulation

\begin{abstract}
Functional drinks containing the leaves of Java tea has been shown to offer many health functionalities, particularly to lower blood glucose levels, due to its bioactive compounds. Nanoencapsulation technology was reported being able to protect these bioactive compounds and also enhance their bioavailability. This study examined the use of nanoencapsulation techniques to improve the bioavailability of Java tea-based functional effervescent drink and enhance its antihyperglycemic activity. Three versions were prepared in this study: ready to drink (RTD) as the control, microencapsulated, and nanoencapsulated. They were all measured for their total phenolic content (TPC) before being tested for their antihyperglycemic activity. The TPC of RTD, microencapsulated, and nanoencapsulated Java tea-based functional drinks (JTFD) were 998,425, 735,433, and $663,517 \mathrm{ppm}$, respectively. The antihyperglycemic activities were evaluated by feeding each beverage to streptozotocin-induced diabetic Sprague Dawley rats for fourteen days. Nanoencapsulated JTFD was found to be more superior than the other two formulations to decrease the blood glucose level $(\mathbf{7 . 9 8 \%})$, maintain the feed intake, body weight, improve the viability of Langerhans and beta-cells by $49.09 \%, 32.50 \%$, respectively.
\end{abstract}

\section{Introduction}

Diabetes mellitus is a group of metabolic diseases portrayed by the rise of blood glucose levels caused by the flaws either in insulin secretion or action. A study proved that diabetes mellitus is caused by oxidative stress resulted from the increase of free radical formation in the body (Ullah et al. 2016). In vitro experiments on animals and humans demonstrated that the oxidative stress in humans and plants causes an elevated formation of free radicals in the pathophysiology resulting in many detrimental effects of diabetes towards renal, retinal neurological, cardiovascular functions (Chaudhuri and Umpierrez 2012).

Orthosiphon aristatus, popularly known as Java tea, showed antihyperglycemic activities and had been utilized to alleviate diabetes conditions by the local Indonesian communities, which resulted in its popularity as alternative antidiabetic medicine

\footnotetext{
* Corresponding Author

E-mail Address: hazemi@indo.net.id
}

(Miltonprabu 2019). Antihyperglycemic effect, observed following administration of Orthosiphon aristatus extract $(1 \mathrm{~g} / \mathrm{kg})$ to streptozotocin (STZ) induced diabetic rat, was similar to that observed with glibenclamide (10 mg/kg) (Mohamed et al. 2011). The antihyperglycemic activities of Orthosiphon aristatus leaves might be due to their flavonoids and phenolic acid content as phytochemicals, which play a role in secondary metabolic compounds in plant protection.

Along with other herbs and spices, Java tea extract had been utilized to produce a functional drink with antioxidant activities and oxidative stress reduction (Wijaya et al. 2007, 2011). The RTD JTFD has been examined for the acute test and reported as relatively harmless (Soho 2014). The addition of ginger (Zingiber officinale) was reported to improve the antihyperglycemic activities of JTFD (Indariani et al. 2014). The increase of mice blood glucose level was suppressed by $25.95 \%$ by feeding the ginger-added drink; however, the blood glucose of mice fed with the drink without ginger increased by up to $91.75 \%$.

Ready-to-drink (RTD) Java tea-based products have its limitations in terms of transportation and 
handling due to its volume and shelf life. These limitations could be addressed by converting it into an effervescent dried powder using nanoencapsulation technology, which allowed for easier handling and longer shelf-life (Cushen et al. 2012). Encapsulation of bioactive ingredients within a polysaccharide is crucial to protect them from degradation by reducing their exposure to unfavorable environmental factors while improving their bioactivities (Fathi et al. 2014).

Chitosan has been used as one of the main polysaccharides to create nanoparticles to improve the sustaining and targeting of drug delivery. Nanoparticles could function as a non-toxic and efficient carrier system while enhancing bioactive compounds' bioavailability within the cells and tissues (Khalil et al. 2016). Nanomaterials of nanoencapsulated JTFD powder consisted of FDAapproved polymers for its human consumption (Sampathkumar et al. 2020).

Nanoencapsulated effervescent JTFD showed particle size reduction by $57.19 \%$ with a polydispersity index of $47.55 \%$, suppressed bitter taste intensity (70.05\%), and had preferable taste than the nonnanoencapsulated one (Wijaya et al. 2013). However, the bioavailability of this nanoencapsulated beverage has not been explored yet. Therefore, this study sought to compare the effectiveness of RTD, nanoencapsulated, and microencapsulated effervescent JTFD to inhibit the hyperglycemic syndrome of STZ-induced diabetic rats.

\section{Materials and Methods}

\subsection{Extract Preparation}

Three types of JTFDs were prepared with the extracts of white-flowered Orthosiphon aristatus leaves (specimen No. BMK0076042016) obtained from Balittro Garden, West Java, Indonesia. On top of that, ginger (Zingiber officinale, specimen No. BMK0043052015), lime (Citrus aurantifolia, specimen No. BMK0202092016), kaffir lime (Citrus hystrix, specimen No. BMK0189092016), lemon (Citrus limon, specimen No. BMK0201092016), turmeric (Curcuma xanthorriza, specimen No. BMK0042072014), and sappan wood (Caesalpinia sappan, specimen No. BMK0120092016) were acquired from a local market in Bogor, West Java, Indonesia. Biopharmaca Research Center (Bogor Agricultural University, Indonesia) conducted all plant identification.

The extraction was performed based on Wijaya et al. (2007) by extracting $30 \mathrm{~g}$ of fresh Java tea leaves in $600 \mathrm{ml}$ of boiling water for $15 \mathrm{~min}$ in a closed pan while $20 \mathrm{~g}$ of sappan wood was extracted in $500 \mathrm{ml}$ boiling water for $15 \mathrm{~min}$ in a closed pan. Ginger (100 $\mathrm{g})$, turmeric (100 g), lime (100 g), lemon (250 g), and kaffir lime (100 g) were extracted separately using a juice extractor without the addition of water.

\subsection{Preparation of JTFD}

\subsubsection{Preparation of RTD JTFD}

RTD sample was prepared according to Febriani (2012) with modifications. Java tea extract $(5.9 \mathrm{ml})$ was added into mixture of extracts that containing sappan wood $(1.05 \mathrm{ml})$, ginger $(1.52 \mathrm{ml})$, turmeric $(0.2 \mathrm{ml})$, lemon $(0.902 \mathrm{ml})$, lime $(3.098 \mathrm{ml})$, and kaffir lime $(1 \mathrm{ml})$. Carboxymethyl cellulose $10 \mathrm{ml}$ $(1 \% \mathrm{w} / \mathrm{v})$ was added to the mixture. Aspartame $0.0425 \mathrm{~g}$, acesulfame $0.0157 \mathrm{~g}$, and sucralose 0.0053 $\mathrm{g}$ were added to the mixture. Water was added to the homogenous mixture until the volume reached $100 \mathrm{ml}$. The concoction was added with sodium bicarbonate $2.16 \mathrm{~g}, 1.08 \mathrm{~g}$ of citric acid, and $0.76 \mathrm{~g}$ of tartaric acid just before feeding.

\subsubsection{Preparation of Microencapsulated JTFD}

Microencapsulated drink was prepared according to Kusumasari (2012). Initially, the drink was prepared similarly to the RTD with the addition of water to $100 \mathrm{ml} .100 \mathrm{~g}$ of $20 \%$ maltodextrin solution $(\mathrm{w} / \mathrm{v})$ was then added, homogenized, and spray dried to produce a microencapsulated powder. The powder was then added with three sweeteners (0.0425 $\mathrm{g}$ aspartame, $0.0157 \mathrm{~g}$ acesulfame, and $0.0053 \mathrm{~g}$ sucralose), along with other ingredients such as 2.16 $\mathrm{g}$ of Na-bicarbonate, $1.08 \mathrm{~g}$ of citric acid, and $0.76 \mathrm{~g}$ of tartaric acid. The dried mixture $( \pm 4 \mathrm{~g})$ was diluted in water, and the volume was measured up to $100 \mathrm{ml}$ before feeding.

\subsubsection{Preparation of Nanoencapsulated JTFD}

Nanoencapsulated JTFD was synthesized by an ionic gelation method, according to Wijaya et al. (2013). Chitosan (Himedia Laboratories, Mumbai, India) solution was prepared by stirring acetic acid (Merck Chemical Company, Darmstadt, Germany) at room temperature for $3 \mathrm{~h}$. This was followed by the addition of emulsifier tween 80 and a crosslinking agent (sodium tripolyphosphate (TPP). The mixture of extracts was concentrated using a rotary evaporator (final volume $=1 / 10$ of initial volume) $($ Febriani 2012).

Emulsifier, crosslinking agent, and concentrated extract mixtures were added slowly by dropping consecutively into the chitosan solution under continuous stirring employing a magnetic stirrer for 3 hours at room temperature up until the nanosuspension had been formed and organic 
solvent had been completely removed. $100 \mathrm{~g}$ of maltodextrin was then added to the nanosuspension before being homogenized for 4 minutes and spray dried (Mini Buchi 190, Flawil, Switzerland) to produce a nanoencapsulated powder. The product was then mixed with sweeteners (0.0425 $\mathrm{g}$ aspartame, 0.0157 $\mathrm{g}$ acesulfame, and $0.0053 \mathrm{~g}$ sucralose), $2.16 \mathrm{~g} \mathrm{Na}-$ bicarbonate, $1.08 \mathrm{~g}$ citric acid, and $0.76 \mathrm{~g}$ of tartaric acid. The dried mixture $( \pm 4 \mathrm{~g})$ was diluted in water, and the volume was measured up to $100 \mathrm{ml}$ before feeding.

\subsection{Particle Size and Polydispersity Index (PDI) Characterization}

Size distributions and the average particle size of nanoencapsulated JTFD was measured using dynamic light scattering(Zetasizer Ver. 7.03, Malvern Instruments, Worcestershire,UK). All measurements were performed in triplicates. About 3 drops of the sample were put in the sample cell, covered and measured using NanoQ software with input data in the form of solvent refractive index and viscosity based on the laser beam's intensity on 30 distinct field points of each sample. The particle size and polydispersity index can be seen from the output of the cumulant method that is PDI (Davies et al. 2020).

\subsection{Scanning Electron Microscope (SEM)}

The morphology of JTFD powder was examined by scanning electron microscopy (SEM, Zeiss EVO MA10). The dry sample was covered with conductive carbon tapes and coated with a thin $(<20 \mathrm{~nm})$ conductive gold layer using a sputter-coater. A $20 \mathrm{kV}$ of voltage was applied with $40 \mathrm{~Pa}$ of pressure and 5,000 times of magnification. The digital image of samples was obtained, and representative images are presented (Nallamuthu et al. 2015).

\subsection{Determination of Total Phenolic Content}

Folin-Ciocalteu reagent was used to establish the total phenolic content (TPC) of all samples based on phenol's ability to reduce the Folin-Ciocalteu phosphomolybdate forming molybdenum blue. Gallic acid was employed as the standard reference (50-250 ppm). $1 \mathrm{ml}$ of each sample was added with $5 \mathrm{ml}$ of water and $0.5 \mathrm{ml}$ of Folin-Ciocalteu reagent (diluted to 50:50 with de-ionized water) before neutralized with $1 \mathrm{ml}$ of sodium carbonate solution $(5 \% \mathrm{w} / \mathrm{v})$. The concoction was kept at room temperature in the absence of light for 1 hour with occasional shaking to develop the final color. The absorbance was assessed by a double beam UV-Vis spectrophotometer (Shimadzu 2450, Kyoto, Japan) at $725 \mathrm{~nm}$. The TPC was calculated using a linear regression equation of a gallic acid standard curve, reported as mean $\pm S D(n=3)$ and conveyed in ppm gallic acid equivalent (GAE) (Al-Owaisi et al. 2014).

\subsection{Animals and Diet}

Sprague Dawley albino male rats with body weights of 200-350 $\mathrm{g}$ (Mestry et al. 2017) were acquired from the experimental animal facility of The National Agency of Drugs and Food Control (BPOM) Republic of Indonesia. They were housed in box cages with wire mesh tops, provided with bedding material from sawdust, and divided into groups of three in a housing system. The rats were fed ad libitum in 50-60\% relative humidity and artificial light (6.00 AM to 6.00 PM) along with a standard diet (14.74\% carbohydrate, $17.31 \%$ protein, $10.63 \%$ fat, $5.88 \%$ water, $31.63 \%$ ashes). Diabetes was induced by intraperitoneal injection of STZ (Sigma Chemical Co., St Louis, MO, USA) at $45 \mathrm{mg} / \mathrm{kg}$ of body weight (Mestry et al. 2017).

STZ in $0.1 \mathrm{M}$ of acetate buffer was induced after fasting for 18 hours. The rats were administered overnight with a $10 \%$ sucrose solution to alleviate STZ-induced hypoglycemia. Rats with a blood glucose level of $\geq 200$ $\mathrm{mg} / \mathrm{dl}$ were deemed diabetic and used in this study (Premanath and Nanjaiah 2015). The experiments were carried out in a qualified animal breeding room in the Animal Laboratory of Tropical Biopharmaca Research Center IPB (Protocol fulfilled the guidelines described in The Animal Ethics Committee, Bogor Agriculture University, and had been approved with registration number: 20-2016 IPB).

\subsubsection{Experimental Groups and Treatments}

All rats were arbitrarily separated into five groups of three (Krayem and Sarker 2017). The groups were assigned as A, B, C, D, E, which consisted of normal rats, diabetic control rats fed with distilled water), diabetic rats fed with RTD drink, diabetic rats with microencapsulated drink, and nanoencapsulated drink, respectively. All liquids were force-fed ( $3.64 \mathrm{ml}$ of 200 $\mathrm{g}$ body weight) by an intragastric tube every morning for 14 days.

Functional drink feeding was started at $48 \mathrm{~h}$ after STZ injection (day 2). Feed intake, body weight, fasting blood glucose level, and physical examinations were determined periodically. The drink quantity was tweaked weekly based on the bodyweight changes to maintain similar doses per $200 \mathrm{~g}$ of body weight over the entire study period.

The amount of feed intake and body weight for all groups was measured on day $-7,0,7$, and 14 . After 16 days of the experiment, the rats were sacrificed through the injection of ketamine (Hospira, Lake Forest, USA) 
at $80 \mathrm{mg} / \mathrm{kg}$ of body weight and xylazine (Syntec, Rio Cotia, Brazil) at $10 \mathrm{mg} / \mathrm{kg}$ of body weight. Pancreas tissue was collected for various experimental analyses (2 rats in each group).

\subsubsection{Testing of Fasting Blood Glucose Level}

Measurements of fasting blood glucose level, expressed in milligram per deciliter of blood, was conducted on day 0 , before the STZ injection, day 2, 9 , and 16 after injection of $45 \mathrm{mg} / \mathrm{kg}$ of body weight. The blood sample obtained from the tail vein of $18 \mathrm{~h}$ fasting rats was obtained to measure the blood glucose level using an electronic glucometer kit (Accu-Chek, Roche diabetes care, Indianapolis, Indiana) (Morakinyo et al. 2015).

\subsubsection{Histopathological Study}

A part of the pancreatic tissue was dissected out and washed with phosphate saline buffer $\mathrm{pH} 7.4$, fixed in $10 \%$ of buffered formal saline, and embedded in paraffin. Fixed sections were cut at $5 \mu \mathrm{m}$ and stained with an immune histochemical assay. The section was examined and photographed under a light microscope, according to Abunasef et al. (2014) methods.

\subsection{4. $\beta$-cell and Langerhans islets viability}

An immunohistochemical assay was applied to analyze the viability of $\beta$-cell and Langerhan's islet. The percentage of cell viability was determined by dividing the cells treated (brown color) by the total number of normal cells in control x $100 \%$ (Ghorbani et al. 2015).

\subsection{Statistical and Analysis of Data}

Statistical significance of the biochemical effects was determined by one-way ANOVA using a general linear model procedure of SPSS version 22 software (SPSS Institute, Inc., Chicago, IL, USA) and Duncan's post hoc test at $95 \%$ confidence intervals.

\section{Results}

\subsection{Particle Size and Morphology Observation of Java Tea Nanoencapsulation}

The particle size and polydispersity index of nanoencapsulated JTFD is presented in Figure 1. The scanning electron microscope image of nanoencapsulated JTFD powder is presented in Figure 2.

\subsection{TPC of Various JTFD}

Figure 3 showed the TPC of RTD, microencapsulated, and nanoencapsulated JTFD, shown as gallic acid equivalent. The result showed that the highest TPC was found in RTD drink, while the lowest one was found in nanoencapsulated one $(\mathrm{p}<0.05)$.

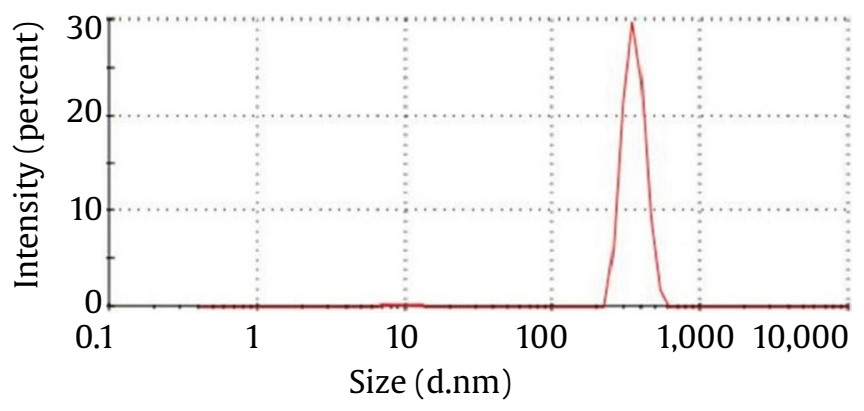

Figure 1 . The diameter avarage and polydispersity index of nanoencapsulated JTFD

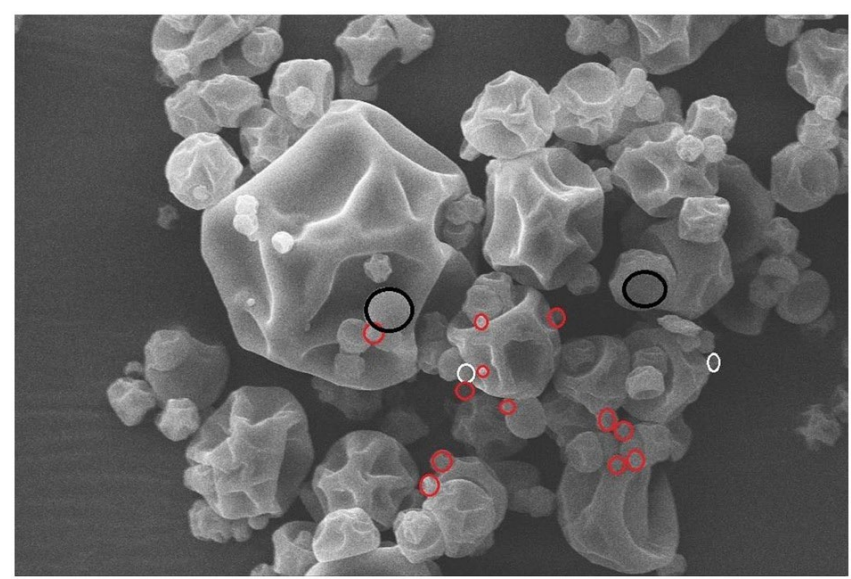

Figure 2. The surface morphology of nanoencapsulated JTFD at magnification of 5,000 X

\subsection{Blood Glucose Level Profile in Rats}

The rat blood glucose level after 14 days of orally administered JTFDs is presented in Figure 4. The study showed that normal glucose levels were between 94-123 $\mathrm{mg} / \mathrm{dl}$. STZ induction caused a significant increase in blood glucose levels $(p<0.05)$ on day 2 when compared with the control (A). Some elevation that was within the normal range of blood glucose levels occurred in control (A) group during the acclimation days with no significant difference $(p<0.05)$. The blood glucose level of STZ-induced rats decreased on day 9 and the percentage of blood glucose level alteration could be seen in Table 1. The blood glucose level of diabetic control (B) rats decreased significantly on day $9(\mathrm{p}<0.05)$. JTFD administration could suppress the blood glucose level on day 9. Nanoencapsulated JTFD was the most effective to suppress blood glucose into a level that was not significantly different $(\mathrm{p}<0.05)$ towards day 2. Diabetic rats treated with microencapsulation (D) and RTD (C) JTFD showed lower blood glucose levels.

The blood glucose level in diabetic control (B) increased significantly $(\mathrm{p}<0.05)$ on day 16 . Meanwhile, as shown in Figure 4, the administration of JTFDs could suppress blood glucose elevation. RTD could suppress 


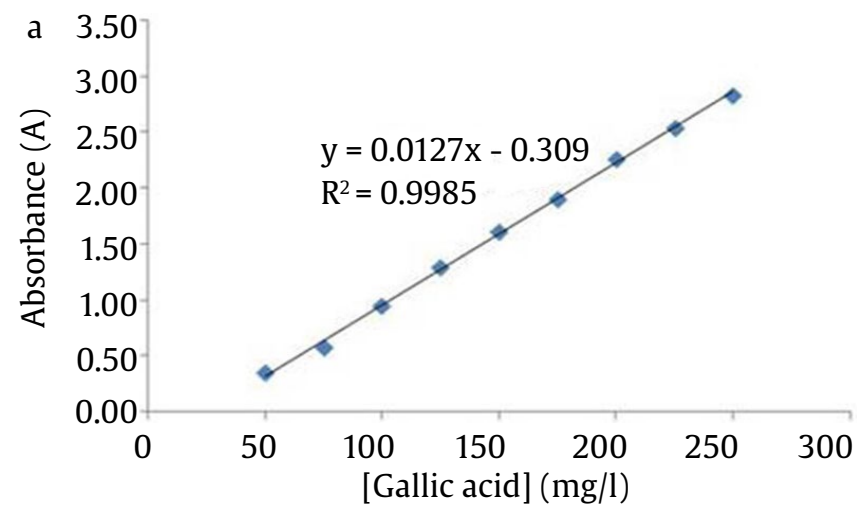

Figure 3. (a) Standard curve and (b) total phenol of 3 type JTFD

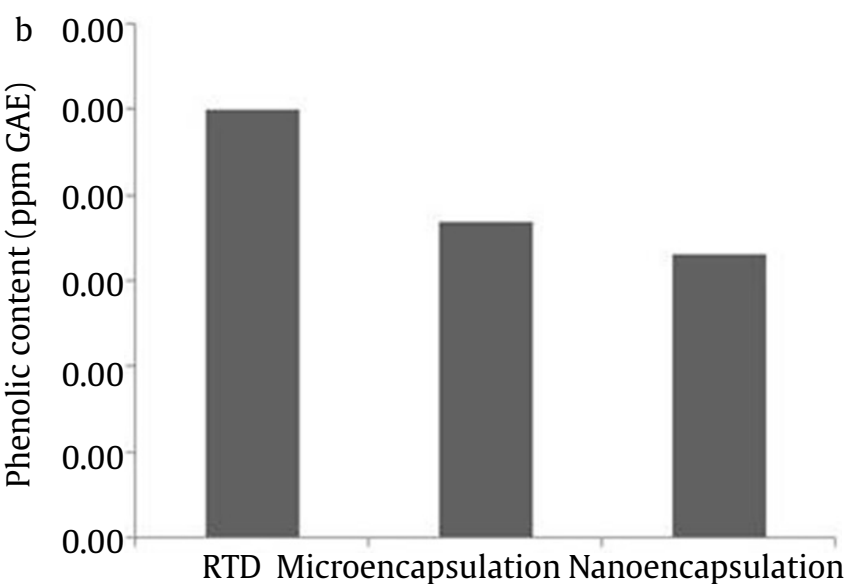

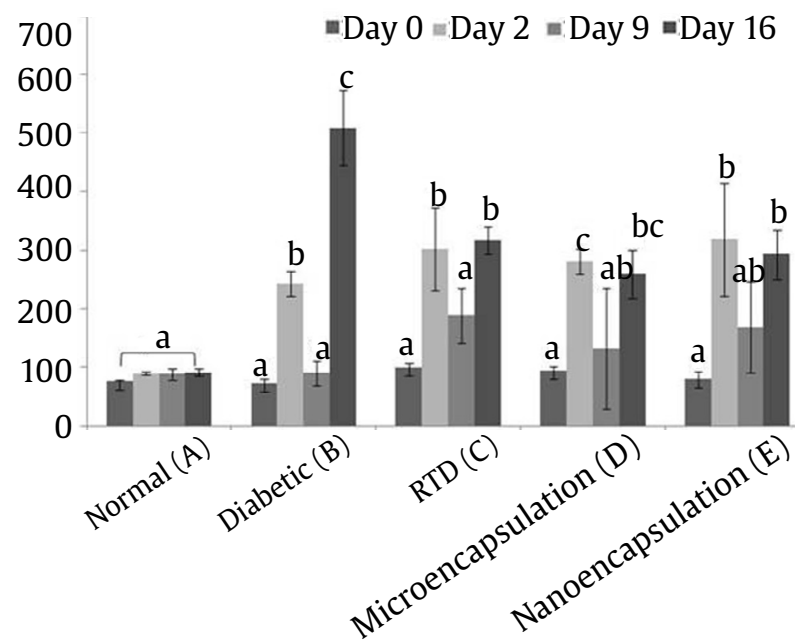

Figure 4. The effect of 3 various kinds of JTFD on blood glucose level of rat (before and during treatment).

the elevation of blood glucose levels; however, it could not lower the elevation of blood glucose levels on day 2 . Microencapsulated and nanoencapsulated JTFDs could slightly reduce blood glucose levels.

The blood glucose-lowering ability of nanoencapsulated JTFD for 14 days seems similar to the microencapsulated JTFD. However, based on the pattern of changes in blood glucose levels during 16 days of the study, the nanoencapsulated JTFD was more effective in stabilizing blood glucose levels than the microencapsulated beverage (Figure 4).

\subsection{Feed Intake of Rats}

During the experimental period, each group's feed intake and body weight were continuously monitored (Figure 5). All rats showed a stable feed intake at 7 days before STZ induction until day 0 . After induced STZ, the feed intake of diabetic rats decreased significantly $(p<0.05)$ from day 0 until day 7 . The decreasing
Table 1. The percentage of decreasing blood glucose during treatment

\begin{tabular}{lrr}
\hline \multirow{2}{*}{$\begin{array}{l}\text { Group of } \\
\text { treatment }\end{array}$} & \multicolumn{2}{c}{ The alteration of blood glucose } \\
\cline { 2 - 3 } & Day 2-9 & Day 2-16 \\
\hline Normal (A) & 1.49 & -2.24 \\
Diabetic (B) & 63.00 & -110.18 \\
RTD (C) & 37.78 & -4.63 \\
Microencapsulation (D) & 53.09 & 7.60 \\
Nanoencapsulation (E) & 42.30 & 7.98 \\
\hline
\end{tabular}

(-) show the increasing of blood glucose level

percentage of feed intake is presented in Table 2 . The highest decreasing feed intake was shown by positive control (B). As shown in Table 2, the administration of all types of JTFDs could suppress the reduction of feed intake. Nanoencapsulated JTFD was the most effective sample to suppress the feed intake reduction compared to other JTFDs while RTD JTFD showed the lowest suppressing effect.

Diabetic control (B) continued to decrease the intake of feed until day 14 , and it was significantly different from day 0 (before STZ induced). The percentage of feed intake was decreasing from day 0 to day 14 . On the contrary, the diabetic rats treated with JTFD showed increasing feed intake until there was no feed left from day 7 to day 14 .

\subsection{Bodyweight of Rats}

The body weight of all rats was continuously observed, as could be seen in Figure 6. The percentage of reduction in body weight from each group is presented in Table 3. Normal control (A) exhibited an increase in body weight significantly $(\mathrm{p}<0.05)$ from 7 days before STZ induction to day 0 , whereas other groups tended to be stable.

STZ induction caused a decrease in body weight from day 0 to day 7 , but it did not show a significant 


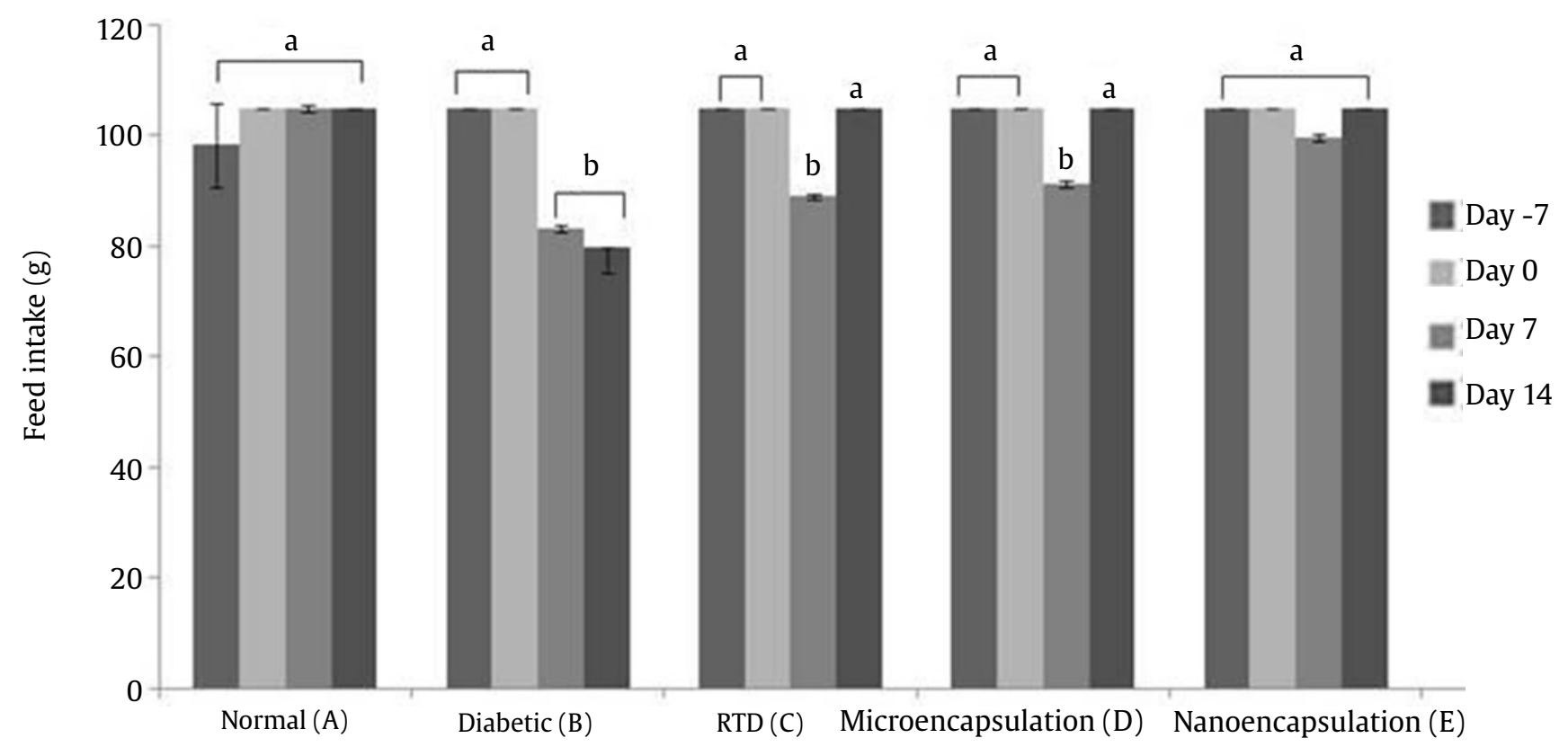

Figure 5. The effect of 3 various kinds of JTFD on feed intake of rat (before and during treatment)

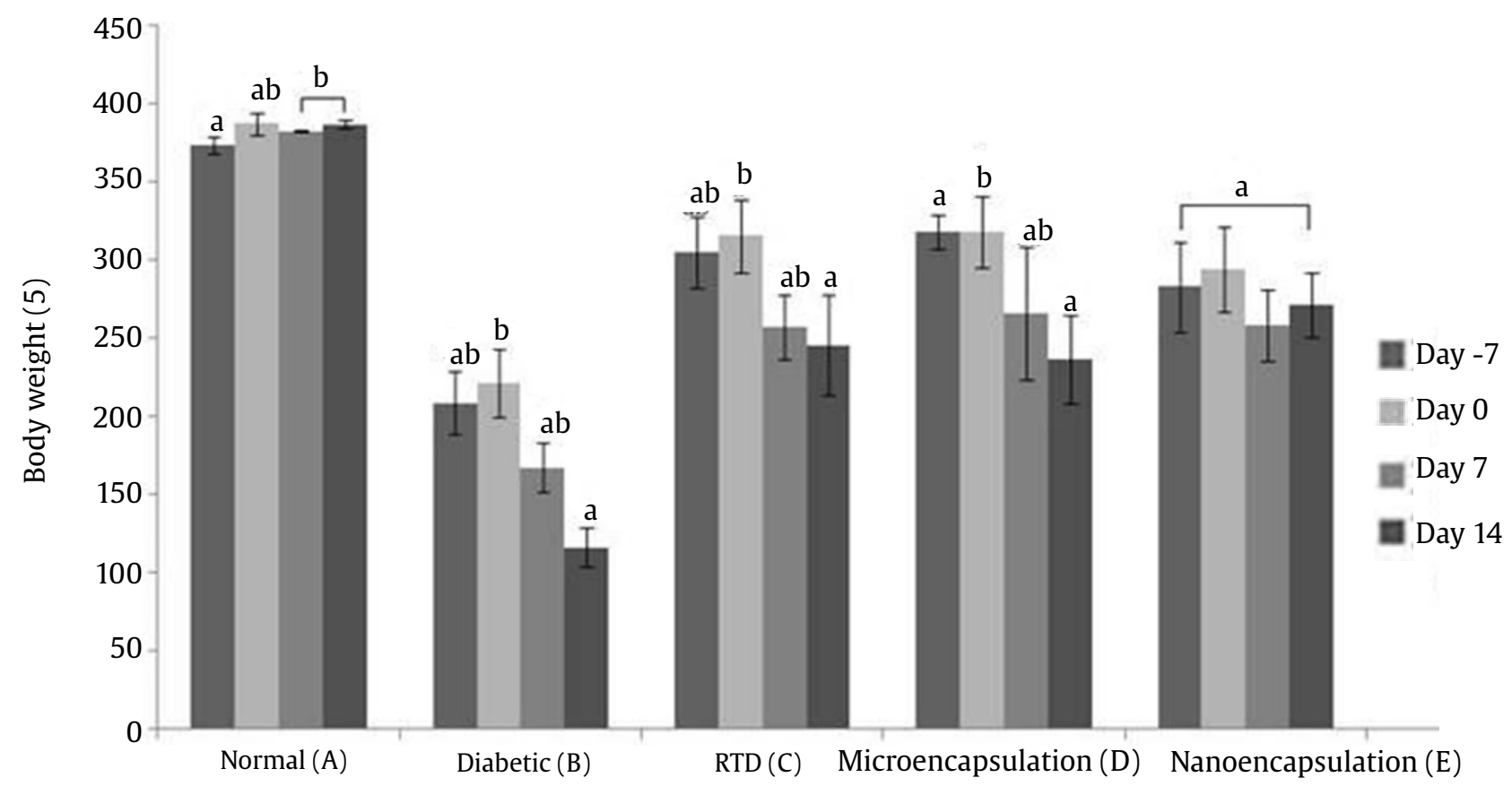

Figure 6. The effect of 3 various kinds of JTFD on body weight of rat (before and during treatment)

Table 2. The percentage of decreasing feed intake during

\begin{tabular}{lcc}
\multicolumn{1}{c}{ treatment } & & \\
\hline Group of & \multicolumn{2}{c}{ Decreasing feed intake (\%) } \\
\cline { 2 - 3 } treatment & Day 0-7 & Day 0-14 \\
\hline Normal (A) & 0 & 0 \\
Diabetic (B) & 20.63 & 24.13 \\
RTD (C) & 15.23 & 0 \\
Microencapsulation (D) & 13.01 & 0 \\
Nanoencapsulation (E) & 5.08 & 0 \\
\hline
\end{tabular}

Table 3. The percentage of decreasing body weight during treatment

\begin{tabular}{lrr}
\hline Group of & \multicolumn{2}{c}{ Decreasing body weight (\%) } \\
\cline { 2 - 3 } treatment & Day 0-7 & Day 0-14 \\
\hline Normal (A) & 1.20 & 0.09 \\
Diabetic (B) & 24.25 & 47.29 \\
RTD (C) & 18.46 & 22.15 \\
Microencapsulation (D) & 16.34 & 25.65 \\
Nanoencapsulation (E) & 12.23 & 7.70 \\
\hline
\end{tabular}


difference $(p<0.05)$. This phenomenon also occurred in control $(A)$. The rats' body weight continued to increase significantly $(\mathrm{p}<0.05)$ until day 14 . It showed that normal control rats' body weight increased significantly $(\mathrm{p}<0.05)$ during acclimation. On the contrary, diabetic control (B) body weight significantly decreased continuously until day 14 .

\subsection{Effect on Langerhans and $\beta$-cell Morphology}

The existence of pancreatic $\beta$-cell was observed by a negative or positive reaction to staining with antiinsulin immunohistochemical methods characterized by the formation of brown color (Figure 7 ). $\beta$-cells that were shrunken showed an adverse reaction towards anti-insulin as it did not form a brown color during preparations. Based on a qualitative immunohistochemical test, the pancreas of normal control (A) showed a strong immunoreactivity towards insulin secreted by $\beta$-cells, as shown by the high intensity of brown color. Diabetic control (B) showed a lack of insulin secretion by the $\beta$-cell in Langerhans islets. The diabetic rats treated with JTFDs showed an increase in the secretion of insulin. As shown in Figure 7, the rats treated with RTD JTFD (C) showed less immunoreactivity than the group treated with a microencapsulated JTFD (D). Diabetic rats treated with nanoencapsulated JTFD (E) showed the most significant regeneration of $\beta$-cell, indicated by increased expression of $\beta$-cell expression compared to the diabetic control (B).
The ability of RTD, microencapsulated, and nanoencapsulated JTFDs in repairing or suppressing the damage of $\beta$-cell compared to the one without JTFD was clearly shown in Figure 7. Quantitatively, the amount of $\beta$-cell and Langerhans islets in immunohistochemical staining can be used to calculate the viability of $\beta$-cell and Langerhans islets (Table 4). The administration of RTD and microencapsulated beverages improved the viability of $\beta$-cells and Langerhans islets than that of positive group (B), but it was not significantly different. Nanoencapsulated beverage significantly maintained the viability of $\beta$-cell function and Langerhans islets $(p<0.05)$ compared to the viability of diabetic control (B).

Table 4. The percentage of $\beta$ cell and Langerhans islet viability

\begin{tabular}{lll}
\hline $\begin{array}{l}\text { Group of } \\
\text { treatment }\end{array}$ & $\begin{array}{l}\beta \text { cell } \\
\text { viability (\%) }\end{array}$ & $\begin{array}{l}\text { Langerhans islet } \\
\text { viability (\%) }\end{array}$ \\
\hline Diabetic (B) & $6.49 \pm 0.89^{\mathrm{a}}$ & $10.00 \pm 00^{\mathrm{a}}$ \\
RTD (C) & $15.95 \pm 8.96^{\mathrm{ab}}$ & $17.50 \pm 7.50^{\mathrm{ab}}$ \\
Microencapsulation (D) & $20.26 \pm 5.85^{\mathrm{ab}}$ & $25.00 \pm 5.00^{\mathrm{ab}}$ \\
Nanoencapsulation (E) & $49.09 \pm 1.77^{\mathrm{b}}$ & $32.50 \pm 7.50^{\mathrm{b}}$
\end{tabular}

Value with same superscript letter within group are not statistically different at significant level of $p<0.05$ by using Duncan test. $a=$ control of viability of $\beta$-cell. $a b$ $=$ able to improve the viability of $\beta$-cell, but it was not significantly different with control. $\mathrm{b}=$ most capable in maintaining the viability of $\beta$-cell
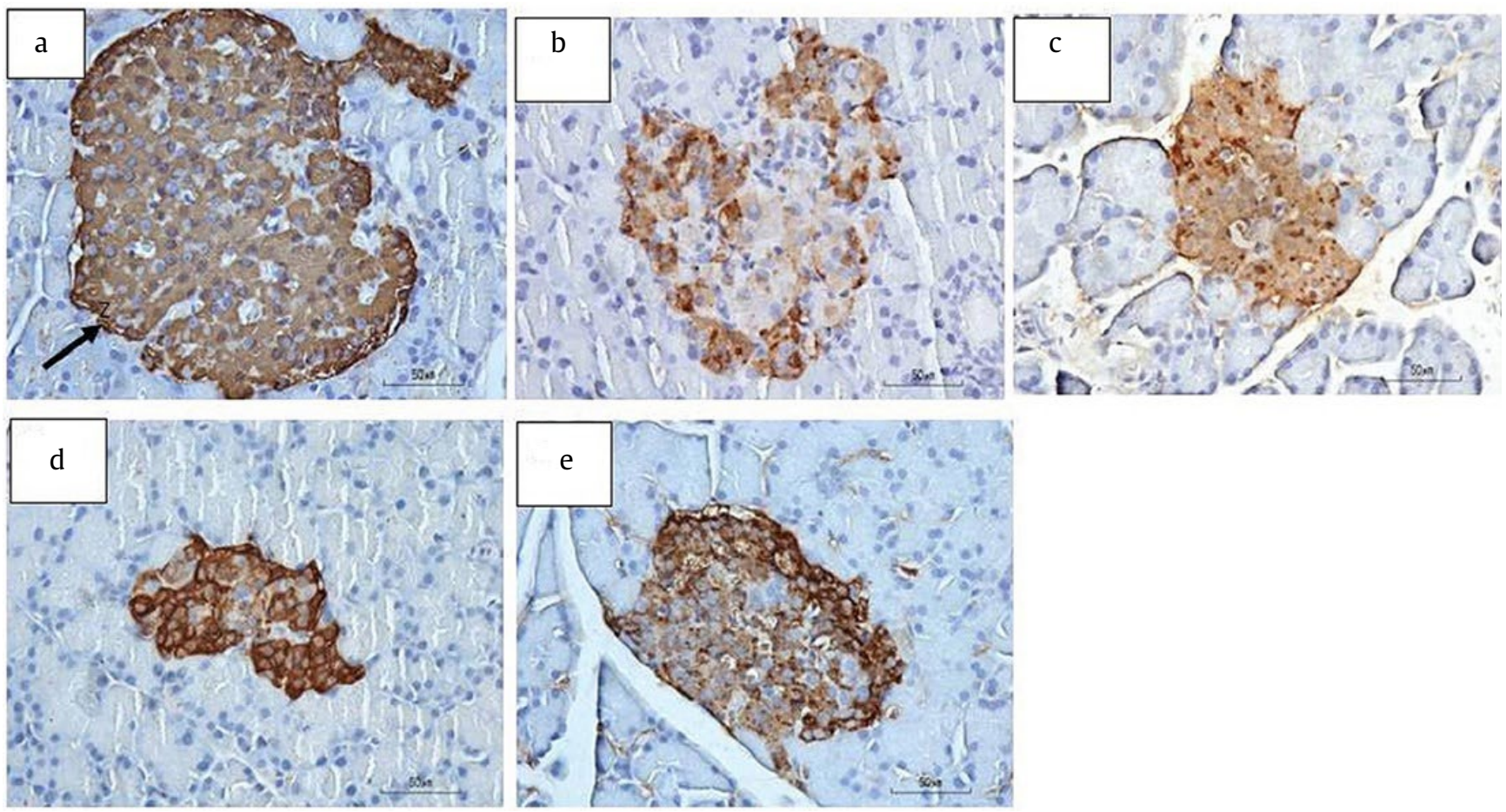

Figure 7. $\beta$ cells in Langerhan with antiinsulin antibody imunohistochemical staining at scale bar $=50 \mu \mathrm{m}$ 


\section{Discussion}

The particles in the nanoencapsulated JTFD were proved as nanoparticles, which is defined as any particulate materials with a size of 1 to $1,000 \mathrm{~nm}$ (Food and Drug Administration 2012). The particle size of the nanoencapsulated drink in this research was larger than that of Wijaya et al. (2013), presumably due to the differences in the degree of deacetylation of chitosan used (Elgadir et al. 2015). The higher degree of deacetylation in chitosan causes stronger break strength, resulting in the smaller size of the nanoparticles (Babii et al. 2020). Wijaya et al. (2013) used chitosan $>90 \%$ degree of deacetylation, whereas this study used $>75 \%$ degree of deacetylation. The concentration of TPP and chitosan is also associated with the increase of particle size. Crosslinking, which connects TPP and chitosan, affects the increase of viscosity and homogenization capabilities, leading to aggregates with large particle size.

Nanoencapsulated JTFD was included in monodisperse systems. PDI represented the particle distribution, where 0.0 represents a narrow distribution, and 1.0 represents an extensive distribution based on Jayapraksha et al. (2016).

The particles of nanoencapsulated JTFD powder were aggregated by melting and attaching. The spherical shape and various sizes of particles are typical of spray-dried powders. This morphology was found in previous observation nanoliposomes loaded with flaxseed-peptide fractions (Sarabandi and Jafari 2020). The full sphere indicates the successful encapsulation process because the bioactive compounds were encapsulated inside the sphere.

Encapsulation might have lowered the total phenolic contents of the encapsulated Java tea-based functional beverages compared to the RTD beverage's total phenolic content. The diffusion mechanism of releasing the active compounds in encapsulated beverages might need longer diffusion time than nonencapsulated. The bioactive compounds, chitosan, and other additives in the nanoencapsulated process have formed in a homogeneous system, causing the least amount of $\mathrm{OH}$ group, which reduced phosphotungstate and phosphomolybdate in the Folin-Ciocalteu reagent utilized in the amount of phenol compounds calculation. Nalamuthu et al. (2015) showed the release of bioactive compounds in encapsulated material runs slower than those in non- encapsulated in an in-vitro test. Moreover, the smaller the particle size, the stronger the contact area and intermolecular forces between the particles would be (Opalinski et al. 2016). Therefore, the process of releasing $\mathrm{OH}$ is more difficult in nanoencapsulated materials than that in microencapsulated materials.

TPC of the RTD sample was more significant than the one found by Indariani et al. (2014), presumably because of the addition of lemon extract. Lemons are rich in phenolic compounds that possess antioxidant activity (Fancello et al. 2016).

All rats had normal blood glucose levels on day 0 based on Yang et al. (2016) study. The increase of blood glucose levels after the STZ-administration (day 2) indicated hyperglycemic conditions (Uma et al. 2014). The reduction of the blood glucose level of diabetic control (B) rats was harmful to rats and should be avoided (Ullah et al. 2016). The decreasing blood glucose level on day 9 in the diabetic group (B) might be caused by the significant reduction of feed intake, resulting in a lower amount of entering nutrients (Pwaniyobo et al. 2020). This decline of glucose levels can be harmful if there is no glucose during starvation, especially when there is no glycogen in the liver. This heavy transitional hypoglycemia results from insulin excess, which is due to STZ induction, causing the lysis of cell membrane, plasma membrane, and other subcellular organelles, including Golgi complex and rough endoplasmic reticulum. The outer and inner membranes of the mitochondria have structural changes in this phase. The expression of functionally essential proteins such as glucose transporter GLUT2, glucokinase, and insulin protein is undetectable (Karim et al. 2012).

The small size of the nanoparticle can increase the beverage's contact surface, which may cause a faster regeneration of $\beta$-cells (Samadder et al. 2012). The administration of nanoencapsulated JTFD for 14 days was more effective in suppressing the increase of blood glucose levels in diabetic rats (declined blood glucose level) than the administration of RTD JTFD (suppressed the elevation of blood glucose). This study proved that the encapsulation improved bioactive compounds' resistance and bioavailability, as reported by Jang et al. (2013). This study supports previous research stating that a decrease of blood glucose level in Mus musculus force-fed with nanoencapsulated extracts of Syzygium jambolanum for 14 days better than that in the diabetic rats fed by extracts of non-encapsulation (Samadder et al. 2012). 
STZ-induced diabetic rats at dose $45 \mathrm{mg} / \mathrm{kg}$ of body weight were characterized by the decline of body weight and feed intake. This result is in accordance to the other group studies, which showed similar weight loss by the administration of Piper crocatum extract beverage $(1,260 \mathrm{mg} / \mathrm{kg}$ body weight $)$ to Sprague Dawley rats induced by STZ $50 \mathrm{mg} / \mathrm{kg}$ body weight and administration of mixed beverage of red betel extract after 14 days (Hasibuan et al. 2016). The decrease in diabetic rats' body weight was caused by reduced glucose metabolism and increased fat metabolism (Guo et al. 2018). During this period, the animal models looked pale and skinny, suffered hair loss, and the hair turned yellow (Adeyi et al. 2012). Administration of JTFD all variants could increase the appetite, resulting in a lower reduction of feed intake than that of diabetic control (B). It showed that JTFD was a good supplement to diabetic rats as indicated by Indariani et al. (2014). Diabetic rats treated with nanoencapsulated JTFD (E) could stabilize their body weight. Microencapsulated beverages showed higher suppression of the reduction of rat body weight than RTD JTFD in 14 days of oral administration. This ability might be due to the fulfillment of energy due to the improvement of glucose absorption by repairing glucose absorption and optimizing fat utilization. The RTD JTFD showed the weakest ability to suppress the decrease in body weight and feed intake.

The induction of STZ could change the pancreatic morphology of rats. Depreciation of Langerhans islet in diabetic rats might be caused by the loss of $\beta$-cell, which allegedly was caused by the alkylation and activity of NO STZ radical in DNA cell (Smirnov et al. 2012). The morphology of Langerhans islet has been reported by Wu et al. (2016). JTFD has been reported to improve Langerhan's islet (Indariani et al. 2014). The ability of nanoencapsulated JTFD as the most effective beverage in repairing the morphology of Langerhans islet (Figure 7) was aligned with its ability to suppress the increase of blood glucose levels and to suppress the decrease of feed intake and body weight.

The increase of $\beta$-cell number allegedly could increase the insulin levels, as reported by Hasibuan et al. (2016). In the present study, nanoencapsulated bioactive compounds might have more significant advantages due to the protection of active compounds on the way towards the target cell, inducing higher bioavailability of bioactive compounds of nanoencapsulated JTFD and due to an increase of the surface area of nanoencapsulated JTFD that improves the cell reparation. This study was in accordance with another study showing that nanoencapsulated Syzygium jambolanum extract resulted in better protection and improvement of L6 cells in diabetic rats induced by arsenic comparing to the nonencapsulated extract (Samadder et al. 2012).

\section{Conclusion}

Java tea-based functional drink (JTFD) was successfully encapsulated using nanoencapsulation technology, and the particles dominantly had spherical shape morphology. All types of JTFDs suppressed the increase of blood glucose levels in diabetic rats. Nanoencapsulated JTFD was the most effective in lowering blood glucose levels, maintaining the feed intake, and stabilizing the body weight of diabetic rats by protecting the viability of $\beta$-cell and the islets of Langerhans. The findings may support the nanoencapsulation of Java tea-based functional effervescent drink as a new way to control blood glucose levels.

\section{Acknowledgements}

The author would like to thank Mrs. Susi Indariani for the supports along the experiment and publication process. This research is part of a long series of studies about Java tea-based functional drinks. It was supported by Director of Research and Community Service, the Directorate General of Higher Education, Ministry of Education no Project 079/SP2H/LT/DPRM/II/2016 (previous research in optimization of the beverage) and the Education Fund Management Institution (LPDP) no Project PRJ797/LPDP/2013 (in vivo analysis of beverage along with next series of studies), Prof. Dr. C Hanny Wijaya, M Agr as the founder.

\section{References}

Abunasef SK et al. 2014. A histological and immunohistochemical study of beta cells in streptozotocin diabetic rats treated with caffeine. Folia Histochemica et Cytobiologica 52:42-50.

Adeyi AO et al. 2012. Rat model of food-induced nonobese-type 2 diabetes mellitus: comparative pathophysiology and histopathology. Int J Physiol Pathophysiol Pharmacol 4:51-58.

Al-Owaisi et al. 2014. GC-MS analysis, determination of total phenolics, flavonoid content and free radical scavenging activities of various crude extracts of Moringa peregrina (Forssk.) Fiori leaves. Asian Pacific J of Trop Biomed 4:964-970. 
Babii 0 et al. 2020. Low molecular weight chitosan nanoparticles for $\mathrm{CpG}$ oligodeoxynucleotides delivery: Impact of molecular weight, degree of deacetylation, and mannosylation on intracellular uptake and cytokine induction. International Journal of Biological Macromolecules 159:46-56.

Chaudhuri A, Umpierrez GE. 2012. Oxidative stress and inflammation in hyperglycemic crises and resolution with insulin: implications for the acute and chronic complications of hyperglycemia. J of Diabetes and Its Complications 26:257-258.

Cushen M et al. 2012. Nanotechnologies in the food industry: recent developments, risks and regulation. Trends in Food Sci and Tech. 24:30-46.

Davies S et al. 2020. Simultaneous nanoencapsulation of lipoic acid and resveratrol with improved antioxidant properties for the skin. Colloids and Surfaces B: Biointerfaces 192:111023. DOI:10.1016/j. colsurfb.2020.111023

Elgadir M et al. 2015. Impact of chitosan composites and chitosan nanoparticle composites on various drug delivery systems: a review.J of Food and Drug Analysis 23:619-629.

Fancello F et al. 2016. Chemical characterization antioxidant capacity and antimicrobial activity against food related microorganisms of Citrus limon var. pompia leaf essential oil. LWT - Food Science and Technology 69:579-585

Fathi $\mathrm{M}$ et al. 2014. Review nanoencapsulation of food ingredients using carbohydrate based delivery systems. Trends in Food Sci and Tech 39:18-39.

Febriani E. 2012. Improving taste of Java Tea based functional drink(Orthosiphon aristatus Bl. Miq) with non-sucrose sweeteners based on optimization of combination several orange varieties [Undergraduate diss]. Bogor, Indonesia: Bogor Agricultural University.

Ghorbani R et al. 2015. The effect of time and temperature on viability and performance of Langerhans islets separated foem Balb/c mouse after death. Adv Biomed Res 4:93.

Guo X et al. 2018. Stability of a type 2 diabetes rat model induced by high-fat diet feeding with low-dose streptozotocin injection. Biomed and Biotechnol 19:559-569.

Hasibuan MS et al. 2016. Antihyperglycemic activity of Piper crocatum leaves and Cinnamomum burmannii bark mixture extract in streptozotocin-induced diabetic rats. J Math Fund Sci 48:178-191.

Indariani S et al. 2014. Antihyperglycemic activity of functional drinks based on Java Tea (Orthosiphon aristatus) in streptozotosin induced diabetic mice. Int Food Research J 21:349-355.

Jang D et al. 2013. Enhanced oral bioavailability and antiasthmatic efficacy of curcumin using redispersible dry emulsion. BioMed Materials and Engineering 23: 957-970.

Jayaprakasha GK et al. 2016. Enhanced colon cancer chemoprevention of curcumin by nanoencapsulation with whey protein. European J of Pharm 789:291-300.

Karim S et al. 2012. Hepatic expression and cellular distribution of the glucose transporter family. World J Gastroenterol 18:6771-6781.

Khalil WKB et al. 2016. Nano-encapsulated form of Citrus medica for osteoporosis treatment in animal model. IJPCR 8:49-59.

Krayem and Sarker 2017. Evaluation of the antidiabetic activity of a novel formulation of functional foods in streptozotocininduced balb/c diabetic mice model. IJSR 6:2088-2096.
Kusumasari S. 2012. Optimization of formula Java Tea based functional drink effervescent (Orthosiphon aristatus Bl.Miq) based on in vitro antihyperglycemic activity [Undergraduate diss]. Bogor, Indonesia: Bogor Agricultural University.

Mestry SN et al. 2017. Attenuation of diabetic nephropathy in streptozotocin-induced diabetic rats by Punica granatum Linn. leaves extract. JTCM 7:273-280.

Miltonprabu S. 2019. Quarcetin: A Flavanol with Versatile Therapeutic Applications and Its Interactions with other Drugs. In: A Nabavi SM and Silva A (Eds.). Nonvitamin and Nonmineral Nutritional Suplements. London: Academic Press. pp. 28-... .

Morakinyo AO et al. 2015. Niacin improves adiponectin secretion, glucose tolerance and insulin sensitivity in diet-induced obese rats. Egyptian J of Basic and Applied Sci 2:261-267.

Mohamed EAH et al. 2011. Antihyperglycemic effect of orthosiphon stamineus benth leaves extract and its bioassay-guided fractions. Molecules 16:3787-3801.

Nallamuthu I et al. 2015. Chlorogenic acid loaded kitosan nanoparticles with sustained release property retained antioxidant activity and enhanced bioavailability. Asian J of Pharm Sci 10:203-211.

Opalinski I et al. 2016. Rheology of moist food powders as affected by moisture content. Powder Technology 294:315-322.

Premanath R, Nanjaiah L. 2015. Antidiabetic and antioxidant potential of andrographis paniculata Nees. leaf ethanol extract in streptozotocin induced diabetic rats. Journal of Applied Pharmaceutical Science 5:69-76.

Pwaniyibo SF et al. 2020. Antidiabetic effects of Ficus Asperifolia in streptozotocin-induced diabetic rats. Journal of Diabetes and Metabolic Disorders 19:605616.

Regulation of Nanotechnology, Food and Drug Administration 2012. Available at: http://apps.americanbar.org.[Date accessed: 15 November 2015]

Sarabandi K, Jafari SM. 2020. Effect of chitosan coating on the properties of nanoliposomes loaded with flaxseedpeptide fractions: stability during spray-drying. Food Chemistry 310:125951.

Samadder A et al. 2012. Ameliorative effects of Syzygium jambolanum extract and its poly (lactic-co-glycolic) acid nano-encapsulated form on arsenic-induced hyperglycemic stress: a multi-parametric evaluation. J Acupunct Meridian Studie 5:310-318.

Sampathkumar K et al. 2020. Review: developing nanodelivery systems for agriculture and food applications with nature-derived polymers. Iscience 23:101055.

Smirnov AV et al. 2012. Pancreatic Islet Beta-Cell Apoptosis in Experimental Diabetes Mellitus. In: A Ntuli TM (Eds.). Apoptosis and Medicine. Available at: https:// www.intechopen.com/books/apoptosis-andmedicine/pancreatic-islet-beta-cell-apoptosis-inexperimental-diabetes-mellitus [Date accessed: 21 March 2018]

Soho PT. 2014. Acute toxicity test of Javatea-based functional drink No: 59/LF/II/2014. Laboratory service center community of Pharmacy Faculty, Universitas Indonesia.

Ullah A et al. 2016. Diabetes mellitus and oxidative stress-a concise review. Saudi Pharmaceutical Journal 24:547553.

Uma C et al. 2014. Antihyperglycemic effect of Codariocalyx motorius modulated carbohydrate metabolic enzyme activities in streptozotocin-induced diabetic rats. J of Functional Foods 11:517-527. 
Wijaya $\mathrm{CH}$ et al. 2007. Formulation and making process of Java Tea-based functional drink (Orthosiphon aristatus). Indonesia Patent No P00200700564. Bogor: Indonesia.

Wijaya CH et al. 2013. Effect of nanoencapsulation on the sensory, physicochemical, and functional quality of Java Tea base functional drink (Orthosiphon aristatus B1. Miq). In: Oktrooi Roosseno and Indonesia Herb Council. Manado: Indonesia.

Wijaya $\mathrm{CH}$ et al. 2011. Inhibition of $\alpha$-glucosidase and $\alpha$-amylase activities of some Indonesia herb: in vitro study. In: The 12th ASEAN Food Conference. Bangkok: BITEC Bagna.
Wu C et al. 2016. Myrciaria cauliflora extracts attenuate diabetic nephropathy involving the Ras signaling pathway in streptozotocin/nicotinamide mice on a high fat diet. J of Food and Drug Analysis 24:136-146. Yang HJ et al. 2016. Methyl jasmolate treated buckwheat sprout powder enhances glucose metabolism by potentiating hepatic insulin signaling in estrogendeficient rats. Nutrition 32:1 29-137. 